\title{
Corne Ducale et Sainte-Chaussette dans la relation de voyage d'Evliyâ Çelebi
}

Corno Ducale and Holy Sock in Evliyâ Çelebi's travelogue

Jean-Louis Bacqué-Grammont

\section{(2) OpenEdition}

\section{Journals}

Édition électronique

URL : https://journals.openedition.org/ceb/4012

DOI : $10.4000 /$ ceb.4012

ISSN : 2261-4184

Éditeur

INALCO

\section{Édition imprimée}

Pagination : 171-176

ISBN : 978-2-85831-205-4

ISSN : 0290-7402

\section{Référence électronique}

Jean-Louis Bacqué-Grammont, «Corne Ducale et Sainte-Chaussette dans la relation de voyage d'Evliyâ Çelebi », Cahiers balkaniques [En ligne], 41 | 2013, mis en ligne le 20 mai 2013, consulté le 06 juillet 2021. URL : http://journals.openedition.org/ceb/4012 ; DOI : https://doi.org/10.4000/ceb.4012

Ce document a été généré automatiquement le 6 juillet 2021.

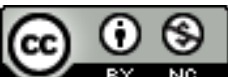

Cahiers balkaniques est mis à disposition selon les termes de la Licence Creative Commons Attribution - Pas d'Utilisation Commerciale 4.0 International. 


\title{
Corne Ducale et Sainte-Chaussette dans la relation de voyage d'Evliyâ Çelebi
}

\author{
Corno Ducale and Holy Sock in Evliyâ Çelebi's travelogue
}

Jean-Louis Bacqué-Grammont

Notre idée première ayant été de parler de «La Bonne-Venise et l'autre d'après Evliyâ Çelebi ", nous nous apprêtions à fureter ici innocemment à travers les étymologies populaires fantaisistes dont cet auteur a truffé à l'envi les dix volumes de son Seyahatnâme, "Relation de voyage ». Mais voilà, comme c'est bien souvent le cas, quelques lignes glanées en rassemblant la documentation nécessaire nous ont soudain transporté bien loin dans le cours de ses voyages. En effet, alors que nous cherchions à en savoir davantage sur le terme Bundukânî appliqué par notre voyageur aussi bien aux ressortissants vénitiens qu'au ducat, la fameuse monnaie d'or de la République de Saint-Marc ${ }^{1}$, une phrase parmi d'autres dans la description de Šibenik Sebenico, sur la côte dalmate, réveilla dans notre mémoire un souvenir récent ${ }^{2}$. En effet, de la manière la plus inattendue, elle rappelait deux longs passages consacrés par notre voyageur au fameux mandylion d'Édesse, textes auxquels nous avons consacré une récente étude ${ }^{3}$. En bref, selon la tradition chrétienne, le mandylion était le linge avec lequel, sur le chemin du Golgotha, une sainte femme nommée Véronique ou Bérénice aurait essuyé le visage en sueur de Jésus, dont l'image serait dès lors demeurée imprégnée sur l'étoffe ${ }^{4}$. Avec quelques hiatus et après beaucoup de péripéties, la présence de cette relique est attestée successivement à Édesse (aujourd'hui şanliurfa, chef-lieu de département en Anatolie orientale), à Constantinople et à Paris où elle fut conservée à la SainteChapelle du milieu du XIII siècle jusqu'à sa disparition au cours des pillages de la Révolution française. Les principales interrogations que soulèvent ces deux passages d'Evliyâ Çelebî sont donc la présence d'une seconde relique de Jésus à Urfa à une date où, s'il s'agit du mandylion, celui-ci devait se trouver à Paris, mais surtout les détails très précis que ces textes fournissent sur cette "empreinte" et qui ne sont guère interprétables qu'à la lumière des technologies les plus modernes. Or, nous trouvons 
ailleurs dans le Seyahatnâme deux allusions relatives à une autre relique qui aurait été conservée dans la même ville d'Urfa à une date imprécise. Il s'agit cette fois du bas ou de la chaussette de Jésus, dont il n'est nulle part question dans le chapitre sur Urfa. De la même manière, le mandylion n'est pas évoqué dans les passages qui concernent ce bas et que l'on va voir. Le premier se situe, comme nous l'avons dit, dans la description de Šibenik. On remarquera que tout ce qu'on y lit est faux ou, du moins, largement inexact ${ }^{5}$ :

Dans les chroniques des mécréants du pays de Venise, c'est le peuple des Bundukânî, c'est-à-dire les nations franques aux perfides stratagèmes et aux belliqueux projectiles, qui ont fondé les premiers [Šibenik]. C'est une construction de celui qui était le bân ${ }^{6}$ et le hersek ${ }^{7}$ du peuple de Venise, un mécréant nommé Pirinç Pîrnîk ${ }^{8}$. Entre les rois de toutes les nations nazaréennes, ces Vénitiens ne sont ni rois, ni hersek, ni bân, ni çârna ${ }^{9}$, ni çâsâr ${ }^{10}$, ni iğrânduk $a^{11}$, ni irşek ${ }^{12}$ (---) (---) (---), mais on appelle pirinc-pîrîm ceux d'entre eux qui détiennent l'autorité (zâabiț). Sur leurs pièces d'or, l'image de mauvais augure [d'un personnage portant] un chapeau court de Hacivât est celle du premier mécréant qui fut pirinç-pîrîm. Mais, selon leur vaine opinion, le tâ $\mathrm{c}^{13} \mathrm{de}$ forme pointue qu'il a sur la tête doit être la chaussette du pas de noble illustration de Monseigneur Jésus, [pas] qui est tombé entre leurs mains dans la ville de Riḳka, c'est-à-dire Urfa, dans le pays du Kurdistan.

Quelques pages plus loin ${ }^{14}$, on trouve un large développement de ce récit :

Exposé des effigies de la pièce d'or vénitienne,

c'est-à-dire la longue effigie placée du côté droit de la pièce d'or de Venise

Après qu'eut lieu cette manifestation des charismes de Mevlânâ, ils le représentèrent sur leurs pièces d'or. C'est l'effigie placée à l'avers ${ }^{15}$ qui est celle des pirinç-pîrîm portant un chapeau assez court comme celui de Ḥâcivâd, c'est-à-dire du roi qui est à la tête des quarante beys ${ }^{16}$. Mais ce qui est sur la tête du pirinç-pîrîm n'est ni un chapeau ni un tâc. C'est le bas de laine de mouton, c'est-à-dire la chaussette, que Monseigneur Jésus - le salut soit sur lui ! - portait à ses pieds de noble illustration et qui, de Rıkka, c'est-à-dire la ville d'Urfa, est passé par un moyen ou un autre entre les mains des Vénitiens. Lorsque l'un des quarante mécréants devient bey pirinç-pîrîm, il s'en coiffe un jour infâme et le conserve. Sur l'une des faces de cette pièce d'or, il est indiqué que la verge de Monseigneur Moïse et la chaussette du Prophète Jésus sont chez eux. Sur cette face, les légendes dans la marge portent les noms de Mevlânâ et du pirinç-pîrîm ${ }^{17}$. Quant à l'autre face, il y a seulement une longue effigie à l'intérieur d'un cercle allongé fait de points et qui est celle de Monseigneur Jésus. Sur les deux liserés des quatre côtés, il y a des points comme des égratignures qui ressemblent aux douze signes du zodiaque: Bélier, Taureau, Gémeaux, Cancer, Lion, Vierge, Balance, Scorpion, Sagittaire, Verseau et Poissons, qui sont douze étoiles comparables aux douze apôtres, vicaires de Monseigneur Jésus, car, il n'y a dans aucun pays mécréant des monastères aussi [savants] en astronomie dans cette Venise. Les légendes qui se trouvent autour de l'effigie du Prophète Jésus sont des salutations et de louanges à son intention, qui disent en latin (---) (suit un blanc)

3 Si l'on prend les éléments dans l'ordre, nous ne dirons rien sur la fondation de Šibenik qui doit se perdre dans l'Antiquité romaine et les ténèbres du haut Moyen Âge, puis dans les dominations croate, hongroise et vénitienne. C'est en tout cas, sous cette dernière qu'elle demeura de 1322 à la fin de la République en 1797, sauf au cours d'une éphémère réoccupation hongroise de 1357 à 1412 . Là n'est pas l'essentiel. Plus intéressante est la longue énumération de ce que n'est pas le doge de Venise. À notre avis, ce qu'Evliyâ comprend difficilement est la nature du régime oligarchique vénitien et son caractère électif viager ${ }^{18}$. Pourtant, la Pologne, le Saint-Empire, Gênes, Dubrovnik, entre autres, pratiquaient des systèmes plus ou moins analogues. Mais ce 
qui diffère fondamentalement de l'usage ottoman est ici l'absence de transmission héréditaire. Certes, dans le monde islamique, les Mamelouks avaient longtemps donné, non sans d'évidents succès, l'exemple de telles successions «méritocratiques». Mais Evliyâ s'en souvenait-il encore ou l'avait-il même médité ? En tout cas, il apparaît bien ici qu'à ses yeux, le doge de Venise n'était pas exactement l'égal des autres souverains de son temps.

On retiendra l'évocation caricaturale qui est faite ensuite du ducat ou sequin vénitien, l'une des monnaies d'or les plus appréciées dans le bassin méditerranéen depuis son apparition à la fin du XIIIe siècle. En fait, comme on vient de le voir, il semble qu'il se présentait différemment de ce qu'on lit ici, mais des émissions durent être faites à l'effigie du doge régnant. Or, ce qui retient avant tout l'attention d'Evliyâ est la coiffure caractéristique de ce dernier, la zoia ou corno ducale dont l'origine demeure incertaine. Pour lui, ce couvre-chef insolite ne peut être qu'un accessoire de bouffonnerie, du fait de sa ressemblance avec ceux de Karagöz et de Hacivat, héros satiriques du théâtre d'ombres turc ${ }^{19}$. À une époque où Venise était le principal adversaire des Ottomans et leur opposait une longue résistance en Crète, tenter ainsi de le ridiculiser par des moyens aussi faciles revenait à dire qu'il n'y avait guère de mérite à le vaincre. Mais, dans ce cas comme dans bien d'autres, Evliyâ semble imperméable à cet aspect des choses.

5 La partie du texte qui nous intéresse ici le plus est celle qui concerne la nature de la relique d'Urfa ${ }^{20}$ qu'évoque pour Evliyâ la coiffure du doge. En effet, nous lisons bien hazret-i 'Îsànuñ kadem-i şerîfi çorabı ola, "ce doit être la chaussette du pas de noble illustration de Monseigneur Jésus ». Si nous comprenons bien, il s'agit, dans l'esprit de l'auteur, d'une sorte d'équivalent de l'empreinte du pied du Prophète Muhammad sur une roche dure, conservée dans le trésor du palais de Topkapı. En effet, nous ne voyons pas d'autre exemple de "pas» (kadem) auquel Evliyâ pourrait penser ici. S'il en est ainsi, ce "pas» avait dû être conservé dans une enveloppe de laine tricotée dont la forme rappelait autant celle d'un " pas » que celle de la zoia. Toutefois, les passages qui nous intéressent se trouvent dans le tome $\mathrm{v}$ du Seyahatnâme, relatant les voyages de 1660. Or, dans les tomes III (voyages de 1648) et VIII (voyages de 1667), c'est incontestablement d'un « linge d'Urfa » et non d'un «pas » ou d'un «bas » que l'auteur parle avec abondance de détails.

6 Provisoirement, il y a donc derrière ces deux reliques l'ombre d'une énigme que nous nous emploierons à résoudre en menant plus avant nos recherches. Mais, dans une correspondance privée, notre collègue et ami Michel Tardieu nous signale que, jusqu'à présent tout au moins, la tradition chrétienne ne connaît aucune relique de Jésus évoquant de près ou de loin la forme d'une chaussette :

Sauf erreur, il n'existe pas de relique du Christ qui serait une chaussette. La raison essentielle est que les reliques correspondent matériellement aux vêtements et attributs des portraits et peintures. Or le Christ est toujours représenté pieds nus puisqu'il est saint. La chaussette n'est pas un indice de sainteté. En revanche, dans ce qui touchait aux pieds, les Byzantins vénéraient les sandales de Jésus ainsi que le linge et/ou les serviettes avec lequel/lesquelles Jésus avait essuyé les pieds de ses disciples, de même que, bien sûr, le bassin du lavement des pieds. Les Vénitiens ont été les grands fournisseurs de reliques. Ils ont même apporté comme telles les trompettes en airain de la prise de Jéricho, ainsi que l'arête dorsale de saint Barlaam (qui n'a jamais existé), qui fut vendue aux Portugais. Evliyâ Çelebi répète peut-être une blague vénitienne. Ce qui est intéressant est qu'une fois de plus la relique soit liée à Urfa. On ne prête qu'aux riches. Le toponyme qui précède le nom 
d'Urfa ne pourrait-il être le nom araméen de la ville, Ruha, Urhay, d'où Urfa en turc? Le tâc ne pourrait-il désigner le prépuce de Jésus, relique vénérable s'il en est?

\section{NOTES}

1. Voir, par ex. Mehmet Zeki Pakalın, Osmanlı Tarih Deyimleri ve Terimleri Sözlüğü [Dictionnaire des expressions et termes d'histoire turque] I, p. 246: Bundiki, "Venedik hükûmet ve parasını gösteren bir tâbirdi" [terme employé à propos du gouvernement et de la monnaie de Venise]. Bundiki était déjà le nom arabe de Venise et venait du grec. Au moyen d'une étymologie populaire inventée pour la circonstance, Evliyâ oppose cette " mauvaise Venise » à la " bonne Venise ", en juxtaposant un adjectif slave et un toponyme d'origine allemande et passé par le hongrois, DôbraVenedîk. La République de Dubrovnik était un fidèle tributaire de l'État ottoman depuis le $\mathrm{XV}^{\mathrm{e}}$ siècle et jouissait en contrepartie d'avantages commerciaux très considérables. Evliyâ emploie également Bundukânî dans un sens géographique. Il parle ainsi de la mer Adriatique comme du "golfe de la mer de Venise, c'est-à-dire la mer du Bundukânî» (bahrr-i Venedîk körfezi ya'nî Bunduḳ̂n̂̂ deñizi). Au $x^{\mathrm{e}}$ siècle, Ibn Hawḳal parlait déjà dans son Șûrat al-'arḍ, "Visage de la Terre ", de cûn al-banâdikîn, «golfe des Vénitiens ", cf. Maria Pia Pedani, Venezia Porta d'Oriente, Bologne, il Mulino, 2010, p. 243-246.

2. La présente étude s'inscrit dans le cadre du programme de recherche «Histoire et sciences auxiliaires de l'histoire ottomane", commun à l'Unité Mixte de Recherche 7192 du Centre National de la Recherche Scientifique (Paris) et à l'Institut Français d'Études Anatoliennes d'Istanbul, et dirigé par l'auteur de ces lignes. Elle est sous presse dans les Actes du colloque international sur Evliyâ Çelebi et l'Europe de son temps, Paris, Institut National des Langues et Civilisations Orientales, 14-15 novembre 2011. Nous exprimons notre reconnaissance à Maria Pia Pedani pour les nombreuses informations qu'elle a bien voulu nous communiquer lors de la mise au point de ce texte.

3. En collaboration avec Michel Tardieu, "Evliyâ Çelebi'ye Göre Urfa'daki Kutsal Mendil", communication présentée au «Symposium International sur şanlıurfa dans la culture turque et mondiale » (Uluslarası Türk ve Dünya Kültüründe şanlıurfa Sempozyumu), şanlıurfa, 14-16 octobre 2010 (sous presse dans les Actes). Version française augmentée en préparation sous le titre «Le linge miraculeux d'Édesse dans la relation du voyageur ottoman Evliyâ Çelebi ». Les deux passages que nous y publions sont tirés de [EÇS], Evliyâ Çelebi Seyahatnâmesi [Relation de voyage d'Evliyâ Çelebi], 10 vol. , Istanbul, Yapı Kredi Yayınları, 1994-2007 : III, p. 95, et vIII, p. 181.

4. Cet épisode n'est nulle part relaté dans les évangiles canoniques, mais la tradition s'en est maintenue jusqu'à nos jours dans l'Église catholique, commémoré à la $\mathrm{VI}^{\mathrm{e}}$ station du «Chemin de croix" ".

5. EÇS, V, p. 252-253 : kavm-ı Bundukânî ya'nî milel-i Fireng-i bed-reng-i seng-i pür-ceng-i Venedîk vilâyeti keferelerinüñ tâ'rîhlerinde bu kal'eyi ibtidâ kavm-ı Venedîge pirinç-pîrîm ya nî bân ve hersek olan Pirinç Pîrnîk nâm bir keferenüñ binâsı-dur bu Venedîk cümle milel-i Naṣârâ krâlları mâ-beyninde ne krâl ve ne hersek ve ne bân ve ne çârna ve ne çâsâr ve ne iğrânduka ve ne irşek (---) (---) (---) ancak bunlaruñ zâbitlerine pirinc-pîrîm dérler kim yaldız altunında bir bodurca Hacivâd külahlı șûret ibtidâ pirinç-pîrîm olan keferenüñ șuver-i menhûsı-dur ammâ başdaki sivri şekilli tâcları kendü zu'm-ı fâsidlerince haẓret-i 'Îsànuñ kadem-i şerîfi çorabı ola kim diyâr-ı Kürdistânda şehr-i Rıkkada ya nî Urfa şehrinde ellerinde 
girmiş ola ve șahîh-dür. Voir Helena Turková, Die Reisen und Streifzüge Evliyā Çelebīs in Dalmatien und Bosnien in der Jahren 1659/61, Prague, Académie des Sciences, 1965, p. 47.

6. [EÇSOS], Robert Dankoff, Evliyâ Çelebi Seyahatnâmesi Okuma Sözlüğü, Istanbul, Yapı Kredi Yayınlar1, 2008, p. 70. Du polonais par le hongrois où ce terme désigne un gouverneur de province.

7. De l'allemand Herzog, « duc ».

8. Ou penc-pîrîm, cf. EÇSOS, p. 192 : le doge de Venise, de l'italien principe primo.

9. Op. cit., p. 89, vraisemblablement du bulgare tsarina.

10. Ou çârsâr, ou çârnâsâr, cf. op. et loc. cit., < Kaiser < Caesar.

11. Grand-duc, cf. op. cit., p. 128 : igrândô, ġıândo.

12. Évêque, < hongrois érsek, « cardinal ", cf. op. cit., p. 131.

13. Mot persan qu'on traduit ordinairement par « couronne », bien qu'il s'agisse d'une sorte de chapeau à larges bords relevés. En turc ottoman, le terme a une connotation plutôt négative car il désigne la coiffure caractéristique des kızılbaş d'Iran, schismatiques et soupçonnés d'usages condamnables.

14. EÇS, V, p. 263 : der-beyân-ı tașvîrât-ı altun-ı bundukânî ya nî Venedîgüñ yaldız altunında olan çubugiuñ șag் țarafindaki uzun tașvîr bu kerâmât-ı Mevlânâ żâhir oldukdan șoñra altunlarına tașvîr étdiler ve çubugiuñ karşu țarafindaki Hacivâd takyeli bodur külâhl tașvîr pirinç-pîrîmleri ya'nî ḳırk 'aded beglerüñ başları olan krâlları tașvîri-dür ammâ pirinç-pîrîmüñ başında olan külâh ve tâc degül-dür hazret-i 'Îsà 'alayhi s-salâmuñ pâ-yı şerîfindeki koyun yüninden kalçın-dur ya'nî çorab-dur kim Rıkḳa ya'nî Urfa şehrinden bir takrîb ile Venedîk eline girmiş-dür ḳırk kefereden biri beg pirinç-pîrîm olduḳda ve bir bed-nâm günlerinde başına geyüp șoñra hifż éderler ve ol altunda olan çubuk haẓret-i Mûsànuñ 'așâsı ve 'Îsâ Nebî çorabı bizde dür 'alâmetin étmişler bu țarafda olan kenâreli hatțlar Mevlânâ ve pirinç-pîrîm ismi hațțları-dur ammâ gerü țarafda yalñızca noḳta nokța müdevverden țûlânîce dẩire içre olan tașvîr-i țavîl bi-zzât hazaret-i 'Îsà șûreti-dür ve cânib-i erba'asında olan iki 'aded kenâresi țırmıḳl nokțalar on iki burûca teşbîh ebrâclar dur kim hamel ve sevr ve cevzâ ve serețân ve esed ve sünbüle ve mîzân ve 'akreb ve kavs ve cedy ve delv ve hût misilli burûc șûretleri-dür ve hazrret-i 'Îsânuñ on iki halîfesi havâriyûnlara mu'âdil on iki ylldılar dur zîrâ bu Venedîkde olan 'ilm-i nücûm bir diyâr keferelerinde deyyâr yok-dur ve 'Îsà Nebî tașvîri ețrâfindaki olan hatțlar cümle hazret-i 'îsàya șalavât üselâm ve ta iyyât hatțlart-dur kim lisân-ı Lâtînce ol hatțlar bu dur (---). Voir Helena Turková, op. cit., p. 81.

15. EÇSOS, p. 94 : çubuk, "madeni paranın yazı veya tura yüzü".

16. Le Conseil des Quarante, le plus important à l'origine mais qui devint par la suite une cour de justice.

17. Il s'agit bien de Mevlânâ Celâlü-ddîn Rûmî, évoqué avant ce passage et qui, selon Evliyâ, aurait reçu des biens votifs (nezir) de la part les Vénitiens. Interrogé sur la licéité de ce don, il aurait répondu par l'affirmative. L'interprétation qu'Evliyâ tire de cet hypothétique épisode est que l'avers du ducat, où l'on voit saint Marc remettre au doge son étendard, représente en fait Mevlânâ. Au revers du ducat, le Christ est entouré d'une mandorle entourée elle-même de la légende : sit tibi Christe datem quem tu regis iste ducatus. Le sequin pesait 3,60 g., dont 3,495 g. d'or fin. On rappelle que les premières émissions de monnaies d'or datent du règne de Soliman le Magnifique. On voit dans les lignes qui suivent comment Evliyâ comprend l'effigie du revers et l'explication zodiacale qu'il en donne.

18. Un demi-siècle plus tard, Na'îmâ (mort en 1716), premier titulaire de la charge d'historiographe impérial (vaḱa $a$-nüvîs), avait une idée beaucoup plus précise. Cf. Tarih-i Naima, éd. Mehmet İpşirli, II, Ankara, Türk Tarih Kurumu, 2007, p. 909), dans la traduction de Maria Pia Pedani, Venezia..., op. cit., p. 254-255 : «Lo sbaglio dell'uso dello stato veneziano è che il sovrano non deriva il suo potere dal sangue ma uno arriva al dogado, che è pari al grado di reame, per diritto di turnazione. Ci sono quaranta signori di rango che non eseguono un comando senza aver raggiunto un accordo. Se uno non è d'accordo fanno un concilio e ripetono il voto dibattendo e 
suggerendo, per convincersi. Per questa causa l'avazamento degli affari per la maggior parte avviene in modo lento. Ma essi spesso sono tutti d'accordo su cose malvagie, sopratutto quando si riuniscono in assemblea di stato. Alcuni di questi signori prima diventano bailo ad Aleppo, bailo a Smirne e infine alla Sublime Porta, quando arriva il loro turno. Essi viaggiano per conoscere la condizione del paese e informarsi su questo. Questi baili vengono cambiati ogni tre anni e la legge impedisce loro di rimanere più a lungo. Quando un bailo diventa esperto in materia di commercio e di viaggi commerciali, allora, riceve la posizione di generale che assomiglia senza esagerazione alla posizione di un beylerbeyi. Epoi se un doge, che è un maiale [ = fortunato come un maiale] muore, il generale diventa doge. » L'élection du doge impliquait une série d'élections de conseils qui élisaient d'autres conseils d'électeurs. Si la charge de doge n'était pas héréditaire, elle tournait entre un petit nombre de familles aristocratiques.

19. Cela rappelle l'attitude de Marie-Thérèse d'Autriche qui, quelques décennies plus tard, refusa d'être couronnée reine de Bohême à Prague, arguant notamment du prétexte que la couronne de ce pays évoquait pour elle une « coiffure de bouffon ".

20. C-à-d Urfa, et non Raḳka, qui se trouve dans le Bilâduşşâm et bien loin en aval sur l'Euphrate. Mais il semble qu'Evliyâ confonde cette ville avec la forteresse de Rûm Ḳal'e, en amont de Birecik et plus proche d'Urfa. Cf. Robert Dankoff et Kaus Kreiser, Materialen zu Evliyâ Çelebi. II. A Guide to the Seyāhat-nāme of Evliyâ Çelebi. Bibliographie raisonnée, Wiesbaden, Ludwig Reichert, 1992, p. 36.

\section{RÉSUMÉS}

Nous trouvons dans le Seyahatnâme deux allusions relatives à une relique conservée dans la ville d'Urfa à une date imprécise, un bas ou une chaussette de Jésus. Cette allusion est liée à la coiffure caractéristique du doge de Venise, la corno ducale, ridicule pour Evliyâ car elle rappelle une chaussette et ressemble aux coiffures de Karagöz et de Hacivat. Jésus allait pieds nus, pas de chaussettes-reliques. Le terme « chaussette " pourrait-il en réalité signifier " pas » ? Le mystère n'est pas éclairci.

In the Seyahatnâme we find two references for a relic kept in Urfa at an uncertain date, stockings or sock of Jesus. This reference is related to the headdress characteristic of the Venitian Doge, the corno ducale, ridiculous according to Evliyâ because it evokes a sock et reminds him the Karagöz and Hacivat hairddresses. But Jesus was walking barefoot, no socks-relics. Could the Word "sock" mean "footprint"? The mystery is not solved. 


\section{INDEX}

Thèmes : Histoire, Histoire des mentalités

motsclestr Evliyâ Çelebi (1611-1682), Seyahatnâme, Kalıntılar, Urfa, Osmanlı İmparatorluğu, Onyedinci yüzyılda, Tarih, Zihniyetlerin Tarihi, Seyahatnameler

Index géographique : Empire ottoman, Urfa

Mots-clés : Evliyâ Çelebi (1611-1682), Evliyâ Çelebi (1611-1682), récit de voyage, Seyahatnâme, Seyahatnâme, reliques

motsclesmk ЕВЛИЈА ЧЕЛЕБИЈА, (1611-1682) СЕЈАХАТНАМЕ, МОШТИ, ОТОМАНСКАТА ИМПЕРИЈА, УРФА, СЕДУЧИАЕСЕТИОТ ВЕК, ИСТОРИЈА, ИСТОРИА НА МЕНТАЛИТЕТ, ПАТЕПИСИ

Keywords : Evliyâ Çelebi (1611-1682), Seyahatnâme, Ottoman Empire, seventeenth century, History of mentalities, travelogues

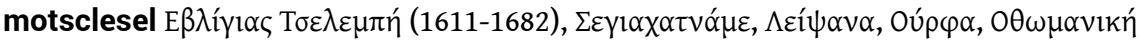

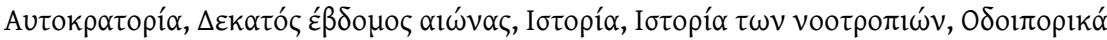
Index chronologique : dix-septième siècle

\section{AUTEUR}

JEAN-LOUIS BACQUÉ-GRAMMONT

Chargé de recherches

CNRS 